\title{
A AUTODECLARAÇÃO E AS MEDIDAS AFIRMATIVAS PARA A PROMOÇÃO DA IGUALDADE RACIAL NO BRASIL
}

\author{
SELF-DECLARATION AND AFFIRMATIVE MEASURES FOR PROMOTING RACIAL \\ EQUALITY IN BRAZIL
}

Dimas Pereira Duarte Junior*

\begin{abstract}
Resumo: As medidas afirmativas para a promoção da igualdade racial têm se mostrado como um importante instrumento na reparação de dívidas históricas deixadas de herança do colonialismo e dos regimes escravocratas ao redor do mundo. O objetivo deste trabalho é analisar o critério da autodeclaração étnico-racial adotado pela legislação brasileira para a implementação de medidas afirmativas voltadas à promoção da igualdade racial. A questão que se pretende enfrentar é: seriam as comissões de verificação de autodeclaração étnico-racial um mecanismo hábil para o controle de fraudes ou serviriam mais como instrumento para desencorajar a autodeclaração e, consequentemente, mitigar a construção da identidade étnico-racial brasileira? A partir da obra de Stuart Hall (2006), busca-se compreender o significado de identidade, pertencimento e autodeterminação como categorias de análise úteis para a compreensão da autodeclaração étnico-racial no Brasil. Trata-se de pesquisa bibliográfica e documental. A metodologia empregada foi de modalidade qualitativa com o emprego de estudo bibliográfico especializado, pesquisa histórica e de dados estatísticos. Parte-se da premissa de que o critério da autodeclaração se apresenta como um instrumento hábil para reforçar a identidade, o pertencimento e o reconhecimento como sujeitos de direito de grupos historicamente alijados do processo de construção de importantes esferas dos espaços públicos e, consequentemente, exercer influência em dimensões que impactam a mobilidade social no país. Por fim, conclui-se que a sistemática da verificação da autodeclaração instituída no Brasil tem se apresentado como um entrave à construção da identidade étnico-racial brasileira.
\end{abstract}

Palavras-chave: Medidas afirmativas; Igualdade racial; Autodeclaração; Identidades; Brasil.

\begin{abstract}
The affirmative actions for the promotion of racial equality, it is showing as an important instrument for repairing historical deviants of the colonialism and the slavery regime around the world. The objective of this paper is to analyze the criterion of ethnic-racial self-declaration adopted by Brazilian legislation for the implementation of affirmative measures aimed at the promotion of racial equality. The question to be addressed is: would ethnic-racial self-declaration verification committees be a skillful mechanism for fraud control, or would they serve more as a tool to discourage self-declaration and thus mitigate the construction of Brazilian ethnic-racial identity? From the work of Stuart Hall (2006), we seek to understand the meaning of identity, belonging and self-determination as useful analysis categories for the understanding of ethnicracial self-declaration in Brazil. It is a bibliographic and documentary research. The methodology used was qualitative with the use of specialized bibliographic study, historical research and statistical data. It is based on the premise that the self-declaration criterion is presented as a skillful instrument to reinforce the identity, belonging and recognition as subjects of rights of groups historically alienated from the process of building important spheres of public spaces and, consequently, to exercise influence on dimensions that impact social mobility in the country. Lastly, it is concluded that the self-declaration verification system established in Brazil has been presented as an obstacle to the construction of the Brazilian ethnic-racial identity.
\end{abstract}

Key-words: Affirmative measures; Racial equality; Self-declaration; Identities; Brazil.

* Doutor em Ciências Sociais: Relações Internacionais pela Pontifícia Universidade Católica de São Paulo - PUC-SP (2008). Mestre em Filosofia Política pela Universidade Federal de Goiás (2001). Graduado em Direito pela Universidade Católica de Goiás (1996). Atualmente, é Professor e Pesquisador do Mestrado em Direitos Humanos da Universidade Tiradentes - UNIT/SE. E-mail: duartejr1@msn.com 


\section{INTRODUÇÃO}

O Brasil, após consagrar constitucionalmente o princípio da igualdade material, de criminalizar atos discriminatórios baseados em raça e estabelecer políticas de ação afirmativa com critérios raciais no âmbito da educação, passou a debater de forma mais geral, apesar de algumas experiências locais e pontuais, a importância de ações afirmativas no mercado de trabalho.

A partir de uma legislação federal ordinária ficou estabelecido o percentual de cotas para negros em concursos federais. Tal legislação foi controlada constitucionalmente pelo Supremo Tribunal Federal, que confirmou a sua constitucionalidade e, por fim, foi regulamentada por ato normativo.

A legalidade e a razoabilidade de critérios para identificação de candidatos negros e pardos para fins de preenchimento de reserva de vagas em concursos públicos é matéria hoje bastante discutida no Brasil, inclusive junto ao Poder Judiciário. Questiona-se, por um lado, se o critério único da autodeclaração seria suficiente. Por outro, indaga-se se o recurso a elementos predominantemente fenotípicos na identificação de candidatos negros é o mais qualificado.

O objetivo deste trabalho é analisar o critério da autodeclaração étnico-racial adotado previsto na legislação brasileira para a implementação de medidas afirmativas voltadas à promoção da igualdade racial à luz da leis 12.711/2012, que dispõe sobre a reserva de vagas para o ingresso nas universidades federais e nas instituições federais de ensino técnico de nível médio, da lei 12.990/2014 que dispõe sobre a reserva de vagas oferecidas nos concursos públicos para provimento de cargos efetivos e empregos públicos no âmbito da administração pública federal, das autarquias, das fundações públicas, das empresas públicas e das sociedades de economia mista controladas pela União, bem como da Orientação Normativa $n^{\circ} 3$ de 01/08/2016, editada pelo Ministério do Planejamento, Desenvolvimento e Gestão que dispõe sobre regras de aferição da veracidade da autodeclaração prestada por candidatos negros para fins do disposto na Lei $n^{\circ} 12.990$, de 9 de junho de 2014.

A questão que se pretende enfrentar é: seriam as comissões de verificação de autodeclaração étnico-racial um mecanismo hábil para o controle de fraudes ou serviriam mais como instrumento para desencorajar a autodeclaração e, consequentemente, mitigar a construção da identidade étnico-racial brasileira?

A partir da obra de Stuart Hall (2006), busca-se compreender o significado de identidade, pertencimento e autodeterminação como categorias de análise úteis para a compreensão da autodeclaração étnico-racial no Brasil. Para tanto, faz uma análise da gênese das medidas afirmativas a fim de entendê-las como políticas públicas, de caráter temporário, transitório e complementar, aptas a compensar perdas históricas sofridas por grupos em situação de vulnerabilidade econômico-social potencializada pela questão étnico-racial (e vice-versa).

A metodologia empregada foi de modalidade qualitativa com o emprego de estudo bibliográfico especializado, pesquisa histórica e de dados estatísticos.

Para efeito desse estudo parte-se da premissa de que o critério da autodeclaração se apresenta como um instrumento hábil a reforçar a identidade, o pertencimento e o reconhecimento como sujeitos de direito de grupos historicamente alijados do processo de construção de importantes 
esferas dos espaços públicos e, consequentemente, exercer influência em dimensões que impactam a mobilidade social no país.

Inicialmente, na primeira seção, propõe-se uma análise das categorias de identidade, pertencimento e autodeterminação étnico-racial sob a perspectiva da obras de Stuart Hall (2006). Na segunda seção adentra no processo de construção do critério da autodeclaração étnico-racial no Brasil. Na terceira seção busca-se compreender à luz de alguns dados estatísticos sistematizados pelo Instituto Brasileiro de Geografia e Estatística (IBGE) a relação entre os critérios da autodeterminação e da heteroclassificação. Ao final é feita uma análise da Orientação Normativa n 3/2016, do Ministério do Planejamento, Desenvolvimento e Gestão adotada, em $1^{\circ}$ agosto de 2016, que estabeleceu as orientações para aferição da veracidade da informação prestada por candidatos negros, que se declararem pretos ou pardos, para fins do disposto no parágrafo único do art. $2^{\circ}$ da Lei $\mathrm{n}^{\mathrm{o}} 12.990 / 2014$.

\section{IDENTIDADE, PERTENCIMENTO E AUTODETERMINAÇÃO ÉTINICO-RACIAL}

No contexto da crítica antiessencialista das concepções étnico-raciais e nacionais da identidade cultural e da política de localização, Stuart Hall (2006) já indagava onde estaria a necessidade de mais uma discussão sobre identidade e, também, quem precisaria dela, restando mais evidente que a atualidade, excepcionalidade e originalidade da discussão talvez não recaíssem na tentativa de identificar quem é membro ou não de um grupo ou coletividade que sofreu os efeitos perversos do colonialismo, do racismo e da exploração, mas sim, o que essas formas de dominação representaram para a sociedade.

Trazendo a discussão para o contexto brasileiro, talvez ficasse mais claro se ao invés de se buscar a resposta para a questão de quem é preto ou pardo, procurássemos compreender o que significa ser preto ou pardo na sociedade brasileira contemporânea.

Para Hall (2006), existem duas formas de se responder essa questão. Uma primeira, sob uma perspectiva desconstrutiva e uma segunda sob a perspectiva discursiva.

\footnotetext{
A primeira consiste em observar a existência de algo que distingue a crítica desconstrutiva a qual muitos destes conceitos essencialistas têm se submetido. Diferentemente daquelas formas de crítica que objetivam superar conceitos inadequados, substituindo-os por conceitos "mais verdadeiros" ou que aspiram à produção de um conhecimento positivo, a perspectiva desconstrutiva coloca certos conceitos-chave "sob rasura" (HALL, 2006, p. 103).
}

Nesse sentido, a identidade seria um desses conceitos que operam "sob rasura", no intervalo entre a inversão e a imergência. Uma ideia que não poder ser pensada da forma antiga, mas sem a qual certas questões-chave não podem ser sequer pensadas.

Sob a perspectiva discursiva, o que se requer é a observância de onde e em relação a qual conjunto de problemas emerge a irredutibilidade do conceito de identidade. O que falta, não é uma teoria do sujeito cognoscente, mas uma teoria da prática discursiva, ou seja, uma reconceptualização do "sujeito", pensando-o a partir de sua nova posição - deslocada ou descentrada - no interior do paradigma (HALL, 2006, 105). 
Por certo que o conceito de identidade se apresenta como demasiado complexo, pouco desenvolvido e menos ainda compreendido, sobretudo quando confrontado com as transformações pelas quais passou a sociedade no final séc. XX, quando paisagens culturais, étnicas, raciais, nacionais, de classe, de gênero e de sexualidade são fragmentadas e promovem um verdadeiro deslocamento dos sujeitos, em si e em relação ao seu lugar no mundo social e cultural (HALL, 2006, p.09).

Nesse sentido, se por um lado, a identidade, na sua acepção sociológica, pode ser vista como o sentimento que preenche os espaços entre o interior e o exterior, ente o mundo pessoal e mundo público, por outro, na sua acepção cultural, dever ser entendida como o sentimento relacionado com o pertencimento a culturas étnicas, raciais, linguísticas, religiosas e, acima de tudo, nacionais (HALL, 2006, p.08).

Para ele,

[...] o fato de que projetamos a "nós próprios nessas identidades culturais, ao mesmo tempo que internalizamos seus significados e valores, tornando-os partes de nós, contribui para alinhar nossos sentimentos subjetivos com os lugares objetivos que ocupamos no mundo social e cultural (HALL, 2006, p.12).

No universo pós-colonial, portanto, a identidade deve ser vista como uma celebração móvel, formada e transformada continuamente em relação às formas pelas quais somos representados ou interpelados nos sistemas culturais que nos rodeiam. É ela que sutura, o sujeito à estrutura. Estabiliza os sujeitos, os mundos culturais que eles habitam, tornando ambos reciprocamente mais unificados e predizíveis (HALL, 2006, p. 12).

Essas identidades, muitas das vezes contraditórias e não resolvidas, fruto da fragmentação e hipersegmentação do sujeito, muito antes de assegurar alguma uma conformidade subjetiva com as necessidades objetivas da cultura, estão entrando em colapso, como resultado de mudanças estruturais e institucionais, abrindo espaço para um modo de identificação muito mais provisório, temporário e problemático que funda um novo sujeito, não fixo, não essencial e não permanente (HALL, 2006, p.12).

A identidade, enquanto categoria de análise das ciências sociais, portanto, não é um dado biológico, mas uma construção social. E quando aplicada à questão étnico-racial em países que passaram por experiências colonialistas, escravagistas e segregacionista, não passa de uma fantasia, pois à medida em que os sistemas de significação cultural se multiplicam, somos confrontados com uma multiplicidade desconcertante e cambiante de identidades possíveis, com cada uma das quais poderíamos nos identificar, ao menos temporariamente (HALL, 2006, p.13).

Seguindo essa concepção, o que se constata é que nenhuma identidade singular seria capaz de alinhar todas as diferentes identidades com uma identidade mestra única e unificante, na qual se pudesse estrutura, por exemplo, uma política afirmativa e promoção da igualdade racial. Afinal, em se tratando de identidade étnico-racial, a forma como o sujeito é interpelado ou representado pode exercer influência direta no ganho ou na perda da própria identidade.

Autodeclaração, portanto, muito antes de ser um critério de classificação e hierarquização étnico-racial deve ser visto como um instrumento de emancipação e autodeterminação do sujeito, erigido não mais a partir das antigas significações da categoria "identidade", mas sim a partir dos conceitos de complexidade, diversidade e diferença, as características da humanidade historica- 
mente suplantadas e subjugadas pelo imperialismo e colonialismo enquanto modelos de sociabilidade dominantes no mundo ocidental.

\section{CONSTRUÇÃO DO CRITÉRIO DA AUTODECLARAÇÃO ETNICO-RACIAL}

As discussões acerca das medidas afirmativas para a promoção da igualdade étnico-racial no Brasil têm provocado intensos debates, sobretudo a partir da ultima década, quando o país adota o Estatuto da Igualdade Racial (Lei 12.288/2010) e as Leis 12.711/2012, que dispõe sobre o ingresso nas universidades federais e nas instituições federais de ensino técnico de nível médio e dá outras providências, e 12.990/2014 que dispõe sobre a reserva aos negros de 20\% (vinte por cento) das vagas oferecidas nos concursos públicos para provimento de cargos efetivos e empregos públicos no âmbito da administração pública federal, das autarquias, das fundações públicas, das empresas públicas e das sociedades de economia mista controladas pela União.

Um dos primeiros debates em âmbito judicial sobre o tema, que emergiram ainda em 2009, foi objeto de uma Arguição de Descumprimento de Preceito Fundamental (ADPF 186) em face de atos administrativos do Conselho de Ensino, Pesquisa e Extensão da Universidade de Brasília, que adotou critérios raciais para o ingresso de alunos na universidade pelo sistema de reserva de vagas. Os atos administrativos e normativos questionados determinaram a reserva de $20 \%$ do total das vagas oferecidas pela universidade a candidatos negros e pardos.

$\mathrm{Na}$ ADPF, os autores alegavam que a política de cotas raciais adotada na Universidade de Brasília feria vários preceitos fundamentais da Constituição Federal, como os princípios republicano (artigo $1^{\circ}$, caput) e da dignidade da pessoa humana (inciso III); repúdio ao racismo (artigo $4^{\circ}$, inciso VIII); igualdade (artigo $5^{\circ}$, incisos I) e legalidade (inciso II). Considerava, ainda, a ação que as medidas representavam ofensa aos princípios da impessoalidade, da razoabilidade, da publicidade e da moralidade, além de dispositivos que estabelecem o direito universal à educação (artigo 205); à igualdade nas condições de acesso ao ensino (artigo 206, caput e inciso I); à autonomia universitária (artigo 207, caput) e ao princípio meritocrático - acesso ao ensino segundo a capacidade de cada um (artigo 208, inciso V).

No embalo dessa discussão muitas outras também foram judicializadas sob o argumento de que feriam os princípios da igualdade, da equidade ou que representavam uma forma de discriminação reversa, pois os contemplados pelo sistema de cotas estariam em vantagem em face daqueles não contemplados pelas medidas ${ }^{1}$.

A discussão judicial em torno do tema foi encerrada em 2012 com o julgamento da ADI 3330 em 2012, pelo Supremo Tribunal Federal que refutou todos os argumentos suscitados e, em síntese, sustentou que tais medidas são coerentes com diversos dispositivos constitucionais que preveem a redução de desigualdades sociais no país, afirmando sua constitucionalidade e seu papel como um importante instrumento de promoção da igualdade material.

Superado o debate judicial que esteve envolto no tema da constitucionalidade das medidas afirmativas para a promoção da igualdade étnico-racial no país, as políticas públicas sobre o tema, respaldadas pelo pronunciamento, em última instância pelo Corte Constitucional Brasileira, ganharam uma nova dimensão, mais ampla e horizontal, pois se até então ficaram restritas ao acesso às 
Universidades, a partir de 2014, com a adoção da Lei 12.990, passam também a balizar o ingresso no serviço público federal naqueles cargos providos por meio de concurso público.

O fato é que, com a adoção dessas medidas em outras esferas da sociedade brasileira, outros debates também passam a ser suscitados. Um deles, que é o objeto dessa análise, é sobre a "autodeclaração étnico-racial" como pressuposto para pleitear o direito de concorrer às vagas reservadas pelas políticas públicas de promoção da igualdade racial no país.

Tanto a Lei $12.711 / 2012^{2}$ quanto a Lei $12.990 / 2014^{3}$ adotaram o critério da autodeclaração étnico-racial por meio do qual ficou estabelecido que podem concorrer às vagas reservadas a candidatos negros aqueles que se autodeclararem pretos ou pardos no ato de sua inscrição no processo seletivo ou concurso público, conforme o quesito cor ou raça utilizado pela Fundação Instituto Brasileiro de Geografia e Estatística - IBGE. ${ }^{4}$

O Brasil, portanto, ao adotar o critério da autodeclaração na investigação étnico-racial de sua população e também em suas políticas públicas para a promoção da igualdade racial, optou por se alinhar às diretrizes presentes nos principais instrumentos internacionais de proteção dos direitos humanos, em especial na Declaração de Durban e na sua Plataforma de Ação, decorrentes da III Conferência Mundial contra o Racismo, a Discriminação Racial, a Xenofobia e as Formas Conexas de Intolerância, realizada em Durban, na África do Sul, entre os dias 31 de agosto e 7 de setembro de 2001.

A Conferência de Durban além de ter se constituído em um marco histórico na política internacional para o enfrentamento da discriminação racial também se revelou como uma oportunidade ímpar para se avaliar e identificar importantes dimensões do racismo e seus efeitos devastadores para a comunidade internacional. As discussões empreendidas naquele fórum impulsionaram significativamente a adoção, o fortalecimento e a promoção de medidas práticas e efetivas de prevenção e promoção da igualdade racial em níveis nacional, regional e internacional.

Ao afirmar a importância dos valores da solidariedade, do respeito mútuo, da tolerância e do multiculturalismo como fundamento moral, ético e jurídico da proteção internacional dos direitos humanos, em especial aqueles relacionados com ao combate e à erradicação do racismo, da discriminação racial, da xenofobia e outras formas de intolerância correlata, a Declaração de Durban e seu Plano de Ação refutaram a doutrina de superioridade racial, reafirmando ser ela cientificamente falsa, moralmente condenável, socialmente injusta e perigosa, e endereçaram aos Estados a obrigação de empreender o máximo de seus esforços para a adoção de medidas administrativas, legislativas e judiciais aptas a rechaçar qualquer tendente a determinar a existência de raças humanas distintas.

Outro aspecto merecedor de destaque na Declaração de Durban e seu Plano de Ação foi o consenso criado em torno do fato de que a discriminação racial, a xenofobia e as formas correlatas de intolerância são situações agravadas pela má distribuição de renda, pela marginalização e pela exclusão social, sendo essas vulnerabilidades decorrentes de um processo de globalização desigual que traz consigo uma série de efeitos negativos que podem acentuar, alimentar e retroalimentar as causas produtoras e reprodutoras da desigualdade, da pobreza, da miséria, da homogeneização cultural e das disparidades econômicas constantemente produzidas segundo critérios raciais, sobretudo em razão da herança de um modelo de sociabilidade colonialista amplamente difundido que 
naturalizou a banalização da escravidão, do tráfico escravo, da servidão, da desumanização e da negação da essência de suas vítimas.

Vale ressaltar que a Declaração de Durban também expressou sua preocupação com a persistência dos efeitos desse modelo de sociabilidade excludente, subjugador, perverso e aniquilador da dignidade humana ainda em pleno Séc. XXI e que boa parte das instituições herdadas não correspondem às características multi-étnicas, pluriculturais e plurilinguais da população, o que, em larga escala, constitui-se num fator impeditivo para a ampliação do conceito de democracia e de espaços públicos em muitos dos países da sociedade internacional.

Nesse sentido, a Declaração de Durban e seu Plano de Ação, em compasso com a Convenção para a eliminação de todas as formas de discriminação racial, adotada pela Assembleia Geral das Nações Unidas em 1965, reafirma a obrigação dos Estados membros da Organização das Nações Unidas de adotarem medidas de repressão, prevenção e promoção voltadas para a eliminação das violações de direitos humanos relacionados com a questão racial e todas as outras formas de discriminação e intolerância correlatas.

Dentre as medidas de repressão merecem destaque: a) a obrigação dos Estados de criminalizar o racismo, a discriminação e outras formas de intolerância correlatas, estabelecendo penas condizentes com o potencial ofensivo que esses tipos penais representam e, ainda, garantir a responsabilização dos seus agentes; b) a obrigação de adotar medidas que façam cessar as causas produtoras e reprodutoras da desigualdade e da discriminação racial; e, c) a obrigação de adotar de medidas para mitigar os efeitos da discriminação nas populações em situação de vulnerabilidade.

No que tange às medidas de prevenção da discriminação e de promoção da sua eliminação, vale ressaltar que a Declaração de Durban e seu Plano de Ação reforçaram a importância e a necessidade de serem adotadas medidas especiais ou medidas positivas em favor das vítimas de racismo, discriminação racial, xenofobia e intolerância correlata com o intuito de promover sua plena integração na sociedade e corrigir as condições impeditivas do gozo dos direitos humanos civis, políticos, econômicos e sociais em igualdade de condições. Dentre elas a adoção de medidas que contribuam para a construção de uma identidade emancipadora capaz de reforçar a autodeterminação de grupos e coletividades historicamente alijados dos espaços públicos e das arenas de exercício da cidadania, reforçando, portanto, os direitos desses grupos à cultura e a sua própria identidade.

Assim, a autodeclaração étnico-racial, enquanto método adotado pelo Brasil para determinar os destinatários das medidas afirmativas para a promoção da igualdade racial é critério que encontra respaldo na Conferência de Durban e seu Plano de Ação e deve levar em conta tanto as variáveis fenotípicas individuais quanto aspectos com maior grau de subjetividade, como raça, língua, cultura, territorialidade e pertencimento. Cumprindo salientar que, para os documentos internacionais acima mencionados, além de classificar, esses critérios devem ter como objetivo último contribuir para a construção e afirmação da identidade de um povo para além dos parâmetros orientadores da tradicional categoria da nacionalidade. 


\title{
3 O CRITÉRIO IBGE DE AUTODECLARAÇÃO ETNICO-RACIAL
}

O caminho percorrido até a afirmação jurídico-formal da autodeclaração étnico-racial como critério de estabelecimento das características da população brasileira foi tortuoso, marcado por fluxos e contra fluxos.

Petruccelli (2013, p.22), afirma que:

\begin{abstract}
Na época da escravidão, nos casos de fuga, por exemplo, os donos de escravos publicavam anúncios de busca com a descrição física mais acurada possível, incluindo os detalhes de nuanças de cor da pele, dos cabelos e outros traços ou marcas, como cicatrizes ou falta de algum membro, para permitir e facilitar a identificação e a recuperação de quem tivesse fugido. Desenvolveu-se, dessa maneira, desde aquela época, uma terminologia de descrição da aparência ou traços físicos das características raciais dos indivíduos.
\end{abstract}

As características fenotípicas, a aparência, os traços físicos, portanto, eram utilizados como instrumento de dominação que facilitavam a captura de escravos que houvessem fugido de seus senhores e é com essa finalidade que se dá o desenvolvimento da terminologia para descrição da aparência que permitiria construir o primeiro conjunto de características étnico-raciais para a identificação da população brasileira.

Petruccelli afirma que o recenseamento de 1872, lançando mão da herança escravagista, além de classificar, também hierarquizou racialmente a população brasileira. Nessa operação censitária, que distinguia a população segundo sua condição civil em livres e escravos, enquanto os primeiros se autoclassificavam quanto à cor, os últimos eram classificados pelos seus donos (PETRUCCELLI, 2013).

No recenseamento de 1890, o fenótipo, de 1872, dá lugar à ideia de misturas, de mestiçagem de raças na classificação pós-abolição da escravatura, abrindo caminho para construção da retórica da mestiçagem que acaba por influenciar a afirmação de uma linguagem ambígua de inclusão e exclusão na nacionalidade brasileira orientada pelo padrão da cor da pele (NASCIMENTO, 2005).

Nos Recenseamentos de 1900 e 1920 não foi incluída a classificação racial e a operação censitária prevista para 1910 não foi realizada. As classificações oficiais somente são retomadas em 1930. No entanto, conforme afirma Petruccelli (2013), mais uma vez, não houve levantamento censitário em virtude da situação política do País, sendo retomada a série apenas em 1940, fortemente marcada por um modelo de autoclassificação fechada, que aceitava como respostas à classificação racial os termos de branco, preto e amarelo, com a instrução de preenchimento orientando que perante qualquer outra resposta fosse lançado um traço no espaço correspondente (PETRUCCELLI, 2013).

Nos Censos Demográficos 1950 e 1960 tem-se a primeira referência explícita ao princípio da autodeclaração, sendo eles os primeiros a orientar, nas instruções de preenchimento, os recenseadores a respeitarem a resposta dada pela pessoa recenseada.

Com exceção do Censo Demográfico 1970, quando a pergunta foi excluída do levantamento, as outras operações censitárias realizadas, em 1980 e 1991, mantiveram a autodeclaração étnico-racial como forma de caracterização da população brasileira. 
Nos Censos de 2000 e 2010 repete-se a forma de classificação, com uma novidade: a conjugação dos critérios da autoatribuição e da heteroclassficação como forma de evidenciar como a população se vê e como é vista e, também, como forma de confrontar essas percepções para a elaboração de políticas públicas de promoção da igualdade racial no país, sendo esse, portanto, o critério a que se referem às Leis 12.711/2012 e 12.990/2014, ambas instituídas com o intuito de estabelecer reserva de vagas na forma de medidas afirmativas como instrumento de correção de distorções históricas e persistentes na sociedade e nas instituições brasileiras.

Os dados relativos à heteroatribuição étnico-racial foram agregados ao sistema do Instituto Brasileiro de Geografia e Estatística - IBGE a partir do ano de 2008, por ocasião da realização da Pesquisa das Características Étnico-Raciais da População - PCERP.

A Pcerp 2008 realizada em seis unidades da federação ${ }^{5}$ teve como finalidade obter informações que pudessem contribuir para o conhecimento das dimensões mais relevantes de categorização de cor ou raça no país e, tendo como objetivos específicos: 1) Ampliar o espectro de compreensão das categorias nas estatísticas oficiais em relação às questões étnico-raciais; 2) Fornecer novos elementos de interpretação para possíveis alternativas de aprimoramento do atual sistema de classificação étnico-racial; 3) Construir uma base empírica que permita subsidiar estudos e análises sobre o tema; 4) Levantar as denominações correntes de cor, raça, etnia e origem de forma mais abrangente e completa, tanto do ponto de vista da composição étnica da população como das diversidades regionais; 5) Identificar as dimensões que definem a construção e o uso desta terminologia; e 6) Correlacionar os níveis de instrução e a posição na ocupação da população entrevistada com os dos pais, segundo os grupos de cor ou raça.

Dentre as orientações contidas no manual do entrevistador, o IBGE fez menção expressa de que apenas a pessoa selecionada poderia fornecer informações sobre si mesmo, de modo a respeitando rigorosamente o princípio da autodeclaração como forma exclusiva de identificação.

Na PCERP de 2008 o critério da heteroclassificação, expresso no item 3.00 do formulário de coleta de dados, no qual o entrevistador procedeu à classificação do entrevistado segundo a cor ou raça, a questão fora deixada de forma aberta ou sem pré-codificação ${ }^{6}$. Há de se sublinhar, todavia, que os entrevistadores não receberam nenhum tipo de instrução nem foram orientados sobre como preencher este quesito.

No que tange à autodeclaração vale ressaltar que os entrevistados foram questionados no item 3.08 do formulário de investigação, sobre as dimensões pelas quais elas próprias e as pessoas, em geral, definem cor ou raça, segundo as Unidades da Federação selecionadas. Para tanto deveriam escolher dentre as seguintes opções: 1) cultura, tradição; 2) traços físicos (cabelo, boca, nariz, etc.); 3 ) origem familiar, antepassados; 4) cor da pele; 5) opção política/ideológica; 6) origem sócio-econômica ou de classe social); e 7) outra.

Para o estudo que aqui se faz, considera-se relevante a apresentação de alguns dos dados obtidos pela PCERP-2008, pois reveladores de uma realidade que não pode ser negligenciada na construção do modelo de caracterização étnico-racial brasileiro.

Segundo os entrevistados, a cor da pele, os traços físicos, a origem familiar e os seus antepassados constituem-se nas principais dimensões pelas quais pessoas, em geral, definem raça e cor no Brasil e também se apresentam como as dimensões preferidas pelos entrevistados para se autoclassificarem. 
Outro dado relevante é o que demonstra ter havido relativa concordância entre os resultados obtidos por meio da auto-atribuição e da heteroclassificação étnico-racial na pesquisa de 2008 quando a cor ou raça em questão é a "branca", "negra" ou "preta". Senão vejamos: enquanto 49\% dos entrevistados se declararam brancos, $56,2 \%$ foram classificados como brancos; enquanto $7,8 \%$ se autodeclararam negros, $8,4 \%$ foram classificados como negros; enquanto $1,4 \%$ se autodeclarou preto, $1,0 \%$ foi classificado como preto pelos entrevistadores.

Por outro lado, quando a cor ou raça em questão foi a morena ou a parda, o grau de discordância entre entrevistado e entrevistado apresentou uma significativa discrepância. Enquanto 21,7\% de declararam morenos, apenas 9,3\% foram classificados como morenos; enquanto $13,6 \%$ se declararam pardos, 22,5\% foram classificados como pardos pelos entrevistadores.

Mas tais resultados se referem à totalidade da amostra, ou seja, sem levar em conta as diferenças entre as unidades da federação que foram selecionadas para compor o universo da pesquisa. Com exceção dos números obtidos quanto à cor ou raça branca, as demais todas apresentaram discrepâncias muitas das vezes significativas, o que acaba por revelar que a forma como a população se vê e a forma como é vista étnica ou racialmente sofre muitas variações regionais.

Tabela 10 - Distribuição das pessoas de 15 anos ou mais de idade, por cor ou raça, de cor ou raça - 2008

\begin{tabular}{|c|c|c|c|c|c|c|c|c|c|}
\hline \multirow{2}{*}{$\begin{array}{l}\text { Unidades da federação } \\
\text { pesquisadas e forma de } \\
\text { classificação de cor ou } \\
\text { raça }\end{array}$} & \multicolumn{9}{|c|}{ Distribuição das pessoas de 15 anos ou mais de idade, por cor ou raça } \\
\hline & Total & Branca & Morena & Parda & Negra & Preta & Amarela & Indígena & Outras \\
\hline
\end{tabular}

\section{TOTAL}

\begin{tabular}{lccccccccc|}
\hline Autoclassificação & 100,0 & 49,0 & 21,7 & 13,6 & 7,8 & 1,4 & 1,5 & 0,4 & 4,6 \\
Heteroclassificação & 100,0 & 56,2 & 9,3 & 22,5 & 8,4 & 1,0 & 1,2 & 0,2 & 1,1
\end{tabular}

AMAZONAS

\begin{tabular}{llllllllll}
\hline Autoclassificação & 100,0 & 16,2 & 49,2 & 23,3 & 3,6 & 1,7 & 1,6 & 1,5 & 2,9 \\
\hline Heteroclassificação & 100,0 & 20,4 & 29,7 & 41,1 & 4,4 & 1,3 & 0,9 & 1,8 & 0,4
\end{tabular}

PARAÍBA

\begin{tabular}{lccccccccc}
\hline Autoclassificação & 100,0 & 31,9 & 45,7 & 10,9 & 4,3 & 0,7 & 0,8 & 0,4 & 5,3 \\
\hline Heteroclassificação & 100,0 & 37,5 & 4,3 & 45,2 & 11,3 & 1,3 & - & - & 0,3
\end{tabular}

SÃO PAULO

\begin{tabular}{lcccccccccc}
\hline Autoclassificação & 100,0 & 51,4 & 19,1 & 14,5 & 8,9 & 1,3 & 1,9 & 0,2 & 2,7 \\
Heteroclassificação & 100,0 & 58,0 & 7,9 & 21,6 & 8,7 & 0,9 & 1,8 & 0,1 & 1,0
\end{tabular}

RIO GRANDE DO SUL

\begin{tabular}{lcccccccccc} 
Autoclassificação & 100,0 & 63,5 & 12,4 & 3,8 & 5,0 & 1,6 & 0,4 & 1,1 & 12,3 \\
\hline Heteroclassificação & 100,0 & 76,0 & 5,6 & 10,0 & 4,7 & 1,5 & 0,1 & 0,2 & 1,9
\end{tabular}


A autodeclaração e as medidas afirmativas para a promoção da igualdade racial no Brasil JUNIOR, D. P. D.

\begin{tabular}{llllllllll}
\hline Autoclassificação & 100,0 & 30,4 & 35,6 & 18,6 & 9,7 & 2,0 & 1,0 & 0,2 & 2,4 \\
\hline Heteroclassificação & 100,0 & 36,9 & 16,4 & 30,4 & 14,6 & 0,7 & 0,1 & 0,8 & 0,2
\end{tabular}

DISTRITO FEDERAL

\begin{tabular}{llllllllll}
\hline Autoclassificação & 100,0 & 29,5 & 21,1 & 29,5 & 10,9 & 0,7 & 1,0 & - & 7,3 \\
\hline Heteroclassificação & 100,0 & 34,0 & 23,8 & 28,0 & 11,8 & - & 0,2 & 0,2 & 1,8 \\
\hline
\end{tabular}

Fonte: IBGE, Diretoria de Pesquisas, Coordenação de População e Indicadores Sociais, Pesquisa das Características Étnico-raciais da População 2008.

Mas quanto a isso, vale ressaltar que, embora os dados possam apontar resultados divergentes na análise das desigualdades raciais associadas à renda, à escolaridade ou à habitação em determinadas regiões, outras análises, ao apontarem para um razoável grau de concordância entre elas, podem sinalizar que a discrepância revela a complexidade do tema relacionado à construção da identidade étnico-racial de um povo, sobretudo quando analisadas em confronto com questões econômicas, sociais e culturais. Em todo caso, o estudo de 2008 concluiu que ainda não se dispõe de informações suficientes para determinar o sentido, a dimensão desta discrepância e seu impacto na caracterização étnico-racial brasileira.

\section{A AUTODECLARAÇÃO E AS COMISSÕES DE VERIFICAÇÃO DE VERACIDA- DE DE DECLARAÇÃO ETNICO-RACIAL}

Ao adotar a autodeclaração étnico-racial como critério das medidas afirmativas constantes das Leis 12.711/2012 e 12.990/2014, o Brasil entra em compasso com os preceitos do direito internacional dos direitos humanos, em especial aqueles previstos na Convenção para a eliminação de todas as formas de discriminação racial como também na Declaração de Durban contra o racismo e seu Plano de Ação de 2006.

No entanto, após a adoção das medidas afirmativas de promoção da igualdade racial previstas nas referidas leis brasileiras, a autodeclaração étnico-racial passou a ser vista como um critério insuficiente e suscetível de falhas, pois, revestido de elevado grau de subjetividade, abrindo caminho para a instituição das comissões de verificação das declarações prestadas por candidatos.

Algumas dessas comissões de verificação foram instituídas por Universidades públicas brasileiras, antes mesmo do surgimento das tentativas de regulamentação e atribuição de algum grau de objetividade à matéria.

Entre os anos de 2004 e 2012, quando a Universidade de Brasília passou a adotar sistema de cotas para ingresso de discentes nos cursos de graduação ofertados pela instituição, um sistema de verificação pautado na análise da foto do candidato para aferição da autodeclaração prestada pelos candidatos causou bastante polêmica. Esse sistema foi alterado no ano de 2007, passando a verificação a ocorrer por meio de entrevista perante uma banca avaliadora, modelo que fora abandonado no ano de 2012 em razão da aprovação e entrada em vigor da Lei 12.711/2012 que estabelecia o critério da autodeclaração e não fazia nenhuma menção a critérios fenotípicos.

Posteriormente outras universidades adotaram o sistema de verificação de autodeclaração, mas somente com o intuito de apurar supostas fraudes decorrentes de denúncias. Atualmente, as 
universidades adotaram o sistema de verificação não mais com o intuito de apuração de denúncias, mas como forma de coibir fraudes no sistema de cotas regido legalmente pelo critério da autodeclaração.

No âmbito do serviço público federal, a discussão caminhou a passos mais céleres. Desde a adoção da Lei 12.990/2014, que instituiu a reserva de vagas para ingresso em cargos da administração pública federal providos por meio de concursos públicos, o critério da autodeclaração étnico-racial foi posto em cheque e tido como insuficiente e propício a fraudes.

Alguns concursos públicos realizados logo após a entrada em vigor da lei 12.990/2014 utilizaram-se do expediente das comissões de verificação de veracidade de declaração étnico-racial, no entanto, pelo fato da lei somente fazer referência à autodeclaração segundo o critério do IBGE, a atuação dessas comissões foi alvo de questionamentos judiciais.

As primeiras decisões judiciais contrárias às comissões de verificação de veracidade da autodeclaração afirmaram sua ilegalidade e afronta ao princípio da impessoalidade, principalmente, diante da ausência de critérios objetivos para aferir a raça do candidato7.

Não demoraram também a surgirem as primeiras decisões favoráveis às comissões de verificação de veracidade de autodeclaração, alegando ser a autodeclaração condição necessária, mas não suficiente para garantir a participação do candidato no certame e que, uma vez prevista no edital do concurso que a autodeclaração deveria ser confirmada perante uma banca com base em critérios fenotípicos, não caberia ao Poder Judiciário intervir para se sobrepor á decisão proferida pela referida comissão.

Com o intuito de preencher a lacuna deixada pela lei, o Ministério do Planejamento, Desenvolvimento e Gestão adota, em $1^{\circ}$ agosto de 2016, a Orientação Normativa n 3/2016, que estabelecer orientação para aferição da veracidade da informação prestada por candidatos negros, que se declararem pretos ou pardos, para fins do disposto no parágrafo único do art. $2^{\circ}$ da Lei ${ }^{\circ}$ $12.990 / 2014^{9}$. A orientação, além de buscar dar amparo para o trabalho de verificação das comissões no âmbito dos concursos públicos federais com reserva de vagas para negros e pardos, afirma que essas comissões somente devem levar em conta os critérios fenotípicos dos candidatos.

Ao tentar dar objetividade, afirmando as características fenotípicas como o único critério, preferiu se corroborar a discussão de quem é negro/pardo no país, ao invés de corroborar a discussão sobre o que isso significa e o quanto interfere na perpetuação da forma insidiosa de racismo, discriminação e exclusão a que a população afrodescendente brasileira foi exposta ao longo de séculos.

Posicionamentos divergentes têm ganhado notoriedade, desde a adoção da orientação normativa. O incontestável é que a escolha entre autodeclaração e heteroclassificação é uma opção entre subjetividades.

Por outro prisma, como afirma a Associação Brasileira de Antropologia, em nota de repúdio publicada em 14 de setembro de 2016, há que se considerar que a redação da orientação normativa

[...] em primeiro lugar, [...] revela um traço marcante da relação do Estado brasileiro para com a sociedade: a suspeição sistemática sobre índoles e legitimidade dos interesses dos cidadãos, fundamentando ações persecutórias e repressivas, e, inclusive, a ameaça de uma eventual acusação por falsidade ideológica. O que fica sugerido quando se afirma, no parágrafo $3^{\circ}$ do inciso IV do artigo $2^{\circ}$ : "Na hipótese de constatação de declaração falsa, 


\begin{abstract}
o candidato será eliminado do concurso sem prejuízo de outras sanções cabíveis". Desta maneira, a orientação estabelece meios de contornar o princípio da autodeclaração disposto na lei no. 12.288/10, pois designa que os editais devem especificar métodos de verificação da veracidade da auto-proclamação, "com a indicação de comissão designada para tal fim, com competência deliberativa". Em outras palavras, a autodeclaração identitária, atribuição que compete ao próprio indivíduo no encontro consigo mesmo, promovendo a superação do preconceito histórico, fica sujeita à confirmação de agentes externos. Em segundo lugar, a normativa se supera quando estabelece que essas "formas e critérios de verificação da veracidade da autodeclaração deverão considerar, tão somente, os aspectos fenotípicos do candidato", a serem verificados obrigatoriamente com a presença do concorrente diante da tal comissão deliberativa, que já vem sendo denominada jocosamente, em diferentes âmbitos, por "tribunal racial". O problema é que tal previsão presume um domínio genérico sobre a capacidade de se posicionar sobre essências identitárias, que não podem ser "avaliadas" externamente, mas que correspondem à ordem das moralidades construídas com base em histórias de vidas individuais ou de grupos específicos que só podem ser da competência daqueles que as experimentam, a começar pelos sujeitos que se auto-declaram.
\end{abstract}

A constatação a que se chega é a de que ao tentar dar legitimidade para os trabalhos das comissões de verificação de veracidade da autodeclaração étnico-racial, se promove a instauração de verdadeiros tribunais raciais para vilipendiar o princípio da autodeclaração como instrumento hábil á construção da identidade étnico-racial brasileira, além de violar frontalmente os princípios do contraditório, da ampla defesa e da dignidade humana, pois enseja a eliminação do candidato do concurso, o expõe à situação mais intimidatória do que a que já fora submetido ao longo de sua vida e esvazia o próprio significado das medidas afirmativas instituídas para a promoção da igualdade racial no país.

Nesse norte, não bastasse toda a argumentação de cunho constitucional, se as disposições legais que regulamentam a matéria, ao instituir o sistema de cotas para negros e pardos, os definiu conforme norteamento do IBGE - vale dizer, a autodeclaração - não pode a orientação normativa eleger critérios exclusivamente fenotípicos para tanto, ainda que sob a justificativa de estar no exercício do poder fiscalizatório e para evitar burla do sistema. Vale, para os efeitos legais, a autodeclaração da cor da pele, posto que, de acordo com a legislação brasileira e a Constituição, não é, e não pode ser função do Estado, determinar a raça de uma pessoa. E o critério do IBGE nunca levou em conta exclusivamente o fenótipo da pessoa.

\title{
CONSIDERAÇÕES FINAIS
}

Ao instituir medidas afirmativas para a promoção da igualdade racial e adotar o critério da autodeclaração étnico-racial o Brasil, do ponto de vista formal-regulatório, dá um importante passo rumo ao enfrentamento das causas produtoras e reprodutoras da discriminação e do racismo.

Além de entrar em compasso com os instrumentos normativos internacionais que tratam do tema, também procura dar uma resposta à dívida histórica que tem com a população afrodescendente ao fomentar a construção de um modelo de nação que não só os excluiu socialmente como também contribuiu para reforçar sua invisibilidade no que tange ao exercício de direitos em condição de igualdade.

O Instituto Brasileiro de Geografia e Estatística ao realizar a Pesquisa das Características Étnico-raciais da população em 2008 e nela incluir o critério da heteroclassificação deixou claro na 
exposição da metodologia da pesquisa que o fez com a intenção de obter informações que pudessem contribuir para o conhecimento das dimensões mais relevantes de categorização de cor ou raça no país e ampliar o espectro de compreensão das categorias nas estatísticas oficiais em relação às questões étnico-raciais, de modo a obter novos elementos de interpretação para possíveis alternativas de aprimoramento do atual sistema de classificação étnico-racial no país.

No entanto, ao instituir as comissões de verificação de veracidade de autodeclaração étnico-racial, sob o escopo de coibir fraudes nos processos seletivos a que se referem as leis 12.711/2012 e 12.990/2014 e impedir que candidatos negros sejam prejudicados por concorrerem com candidatos que falsamente se autodeclarem negros, o país retrocede social e juridicamente, pois reforça fatos em detrimento de dados no que diz respeito ao caráter empoderador e emancipatório das políticas públicas de promoção da igualdade racial no país.

E ainda, ao editar a Orientação Normativa $n^{\circ} 3$ em $1^{\circ}$ de agosto de 2016, o Ministério do Planejamento, Desenvolvimento e Gestão, com a intenção de estabelecer orientações para aferição da veracidade da informação prestada por candidatos negros, que se declararem pretos ou pardos, para fins do disposto no parágrafo único do art. $2^{\circ}$ da Lei $n^{\circ} 12.990$, de 2014, o país retrocede ainda mais, pois passa a adotar como formas e critérios de verificação da veracidade da autodeclaração, tão somente, os aspectos fenotípicos do candidato, os quais deverão ser verificados obrigatoriamente com a presença do candidato, reforça o estigma de que a declaração do destinatário da medida afirmativa é insuficiente para seu reconhecimento como sujeito de direito e despreza o fato de que a classificação, do ponto de vista da percepção de traços físicos, condiciona a trajetória de vida de cada indivíduo, podendo resultar em estigmas e desvantagens para uns e capital social para outros. Trata-se, claramente, de uma medida de desencorajamento da autodeclaração, que passa a ser vista como uma potencial declaração falsa e passível de responsabilização criminal.

Em que pese o fato de que, conforme disposto no $\S 2^{\circ}$ do artigo $2^{\circ}$ da Orientação Normativa $n^{\circ} 3$ fazer menção expressa de que a comissão de verificação de veracidade de autodeclaração étnico-racial deverá ter seus membros distribuídos por gênero, cor e, preferencialmente, naturalidade, há de se considerar também a previsão do $\S 3^{\circ}$ do mesmo artigo, ao dispor que na hipótese de constatação de declaração falsa, o candidato será eliminado do concurso sem prejuízo de outras sanções cabíveis, se apresenta como uma medida que muito antes de contribuir para o aperfeiçoamento das medidas afirmativas, evidencia um sistema de tripla penalização.

A primeira penalização seria porque a verificação de veracidade da declaração não contribui para a eliminação do estigma que ainda representa se declarar negro, preto ou pardo na sociedade brasileira. A segunda seria porque além de ameaçar excluir o candidato do certame também prevê sua responsabilização em outras esferas. E, terceiro porque reforça o caráter de prevalência da heteroclassificação sobre a autodeclaração.

Por certo que a autodeclaração não é critério absoluto de definição da pertença étnico-racial de um indivíduo, devendo, notadamente no caso da política de cotas, ser complementado por mecanismos heterônomos de verificação de autenticidade das informações declaradas, tendo o STF, no julgamento da ADPF 186, se pronunciado especificamente sobre a legitimidade do sistema misto de identificação racial.

Certo também é que se basear exclusivamente em critérios fenotípicos para determinar a pertença étnico-racial de uma população não só contraria todos os estudos acerca dos processos 
de construção de identidade já realizados como também contribui, em larga escala para esvaziar o significado das medidas afirmativas de promoção da igualdade racial, pois acabem por reforçar o estigma de que se constituem em algum tipo de privilégio e favorecimento de um grupo e negar o seu papel de instrumento hábil na construção de identidade étnico-racial de um povo.

Os critérios fenotípicos, de forma isolada, longe de promover a tão desejada objetividade científica, conforme previsto na orientação normativa $\mathrm{n}^{0} 3$ do Ministério do Planejamento, Desenvolvimento e Gestão, para orientar a ação das comissões de verificações, além de cientificamente frágil e insuficiente, se prestar a revelar apenas uma face do racismo, da discriminação e da subjugação que é aquela associada à cor da pele e das características físicas.

Partir da premissa de que a medida afirmativa abre caminhos para a fraude e favorecimento em nada contribui para o incentivo ao auto reconhecimento como forma de suplantar o racismo insidioso, camuflado e dissimulado por direitos distorcidos que exortam valores relacionados com o preconceito, com o ódio, com a exploração, com a escravidão e outras formas de violência a partir das quais se erigiu um modelo de sociabilidade colonialista e imperialista. Modelo que deixou de herança uma dívida histórica para com a população afrodescendente no Brasil e que a impede o alcance da igualdade material e o exercício em condições de igualdade de direitos humanos civis, políticos, econômicos, sociais e culturais.

Afinal, como assevera Osório (2003), no fundo, a opção pela auto-atribuição ou pela heteroatribuição de pertença racial é uma escolha entre subjetividades: a do próprio sujeito da classificação ou a do observador externo. A Heteroatribuição não é mais objetiva que a auto-atribuição, pois se os problemas em relação à auto-atribuição são ocasionados pelas características particulares da ideologia racista brasileira, que permitiria a mudança da linha de cor para os mais abastados e/ou para os que possuem poucos traços da ascendência africana, não há nenhuma garantia a priori de que os entrevistadores também não venham a branquear os entrevistados mais ricos e os tipos de aparência limítrofe.

\section{NOTAS}

1 Doutor em Ciências Sociais: Relações Internacionais pela Pontifícia Universidade Católica de São Paulo - PUC-SP (2008). Mestre em Filosofia Política pela Universidade Federal de Goiás (2001). Graduado em Direito pela Universidade Católica de Goiás (1996). Atualmente, é Professor e Pesquisador do Mestrado em Direitos Humanos da Universidade Tiradentes - UNIT/SE

2 Nesse contexto merecem destaque: a) O Recurso Extraordinário $\mathrm{n}^{\circ}$ 597285, interposto contra acórdão do Tribunal Regional Federal da $4^{\text {a }}$ Região, que entendeu ser constitucional o programa de ação afirmativa estabelecido pela Universidade Federal do Rio Grande do Sul - UFRGS, que instituiu o sistema de "cotas" com reserva de vagas como meio de ingresso em seus cursos de nível superior.; e b) a Ação Direta de Inconstitucionalidade $n^{\circ} 3330$ ajuizada pela Confederação Nacional dos Estabelecimentos de Ensino (Confenen), que questionava a Medida Provisória $n^{\circ}$ 213/04, convertida na Lei $n^{\circ}$ 11.096/2005 e que instituiu o Programa Universidade para Todos (ProUni) e passou a regular a atuação de entidades de assistência social no ensino superior. O julgamento desta ADI foi anexada a ADI 3314, proposta pelo partido DEM, por ter exatamente o mesmo objeto, sendo também, portanto, julgada improcedente em maio de 2012.

3 Art. $3^{\circ}$ Em cada instituição federal de ensino superior, as vagas de que trata o art. 10 desta Lei serão preenchidas, por curso e turno, por autodeclarados pretos, pardos e indígenas e por pessoas com deficiência, 
nos termos da legislação, em proporção ao total de vagas no mínimo igual à proporção respectiva de pretos, pardos, indígenas e pessoas com deficiência na população da unidade da Federação onde está instalada a instituição, segundo o último censo da Fundação Instituto Brasileiro de Geografia e Estatística - IBGE.

4 Art. $2^{\circ}$ Poderão concorrer às vagas reservadas a candidatos negros aqueles que se autodeclararem pretos ou pardos no ato da inscrição no concurso público, conforme o quesito cor ou raça utilizado pela Fundação Instituto Brasileiro de Geografia e Estatística - IBGE.

6 Amazonas, Paraíba, São Paulo, Rio Grande do Sul, Mato Grosso e Distrito Federal

7 A pergunta contida no item 3.00 do formulário é: Para você, entrevistador, qual é a cor ou raça da pessoa entrevistada?

8 Decisão emblemática fora proferida pelo juiz Federal Substituto Gustavo Chies Cignachi, da $3^{\text {a }}$ vara Federal da Subseção Judiciária de Santa Maria - RS, nos autos do processo no 5000923-98.2015.4.04.7102/ $\mathrm{RS}$, que considerou as comissões verdadeiros tribunais raciais.

9 Decisão também emblemática proferida pelo TRF3 nos autos do Agravo de Instrumento ai199062920154030000-ms-0019906-2920154030000, publicada em 11/03/2016, que afirmou não ser passível de revisão judicial de critério subjetivo de resultado de prova, que originariamente cabe à banca.

10 Art. $2^{\circ}$ - Nos editais de concurso público para provimento de cargos efetivos e empregos públicos no âmbito da administração pública federal, das autarquias, das fundações públicas, das empresas públicas e das sociedades de economia mista controladas pela União deverão ser abordados os seguintes aspectos: I - especificar que as informações prestadas no momento da inscrição são de inteira responsabilidade do candidato; II - prever e detalhar os métodos de verificação da veracidade da autodeclaração, com a indicação de comissão designada para tal fim, com competência deliberativa; III - informar em que momento, obrigatoriamente antes da homologação do resultado final do concurso público, se dará a verificação da veracidade da autodeclaração; e IV - prever a possibilidade de recurso para candidatos não considerados pretos ou pardos após decisão da comissão. $\S 1^{\circ}$ - As formas e critérios de verificação da veracidade da autodeclaração deverão considerar, tão somente, os aspectos fenotípicos do candidato, os quais serão verificados obrigatoriamente com a presença do candidato. $\S 2^{\circ}$ - A comissão designada para a verificação da veracidade da autodeclaração deverá ter seus membros distribuídos por gênero, cor e, preferencialmente, naturalidade. $\S 3^{\circ}$ - Na hipótese de constatação de declaração falsa, o candidato será eliminado do concurso sem prejuízo de outras sanções cabíveis.

\section{REFERÊNCIAS BIBLIOGRÁFICAS}

ALVES, José Augusto Lindgren. Os direitos humanos na pós-modernidade. São Paulo: Perspectiva, 2005.

ABA. Nota da Associação Brasileira de Antropologia (ABA). Repúdio à Orientação Normativa $n^{\circ} .3$, de 1o. de agosto de 2016, do Ministério do Planejamento, Desenvolvimento e Gestão, contra Programa de Promoção da Igualdade Racial. Disponível em: http://conflitosambientaismg.lcc.ufmg.br/noticias/nota-da-associacao-brasileira-de-antropologia-aba/. Acessado em 05/03/2018.

BRASIL. Constituição Federal de 1988.

. Lei 12.288/2010. Institui Institui o Estatuto da Igualdade Racial; altera as Leis nos 7.716, de 5 de janeiro de 1989, 9.029, de 13 de abril de 1995, 7.347, de 24 de julho de 1985, e 10.778, de 24 de novembro de 2003. Disponível em: http://www.planalto.gov.br/ccivil_03/_ato2007-2010/2010/lei/112288.htm Acessado em 14/10/2014

Lei 12.990/2014. Reserva aos negros $20 \%$ (vinte por cento) das vagas oferecidas nos concursos públicos para provimento de cargos efetivos e empregos públicos no âmbito da administração pública federal, das autarquias, das fundações públicas, das empresas públicas e das sociedades de economia mista contro- 
ladas pela União. Disponível em: http://www.planalto.gov.br/ccivil_03/_ato2011-2014/2014/lei/112990.htm Acessado em 14/10/2014

Lei 12.2711/2012. Dispõe sobre o ingresso nas universidades federais e nas instituições federais de ensino técnico de nível médio e dá outras providências. Disponível em: http://www.planalto.gov.br/ccivil_03/_ato2011-2014/2012/lei/112711.htm Acessado em 14/10/2014

. Ministério do Planejamento, Desenvolvimento e Gestão. Secretaria de Gestão de Pessoas e Relações do Trabalho no Serviço Público. Orientação normativa $n^{\circ} 3$, de $1^{\circ}$ de agosto de 2016. Disponível em http:// www.in.gov.br/materia/-/asset_publisher/Kujrw0TZC2Mb/content/id/23376081/do1-2016-08-02-orientacao-normativa-n-3-de-1-de-agosto-de-2016-23375906 Acessado em 14/10/2019.

HALL, Stuart. A identidade cultural da pós-modernidade. 11. ed. Tradução Thomas Tadeu da Silva e Guacira Lopes Louro. Rio de Janeiro: DP\&A Ed. 2006.

IBGE. Características Étnico-raciais da População: um estudo das categorias de classificação de cor ou raça. 2008. Rio de Janeiro, 2011.

IBGE. Pesquisa das Características Étnico-raciais da População: um estudo das categorias de classificação de cor ou raça PCERP - 2008. Manual do Entrevistador. Rio de Janeiro, jun. 2008.

IBGE. Pesquisa das características étnico-raciais da população - 2008. Questionário. Diretoria de Pesquisas - DPE Coordenação de População e Indicadores Sociais - COPIS. Rio de Janeiro, jun. 2008.

LIMA, Maria Batista. Identidade étnico/racial no Brasil: uma reflexão teórico-metodológica. Revista Forum Identidades. Ano 2, Volume 3 - p. 33-46 - jan-jun de 2008.

ONU. Conferência Mundial contra o Racismo, Discriminação Racial, Xenofobia e Intolerância Correlata. Declaração e Programa de Ação. Durban, 2001.

OSORIO, Rafael Guerreiro. O sistema classificatório de "cor ou raça” do IBGE. IPEA: Brasília, novembro de 2003.

PETRUCCELLI, José Luis; SABOIA, Ana Lúcia (orgs). Características étnico-raciais da população: classificações e identidades. Estudos e Análises Informação Demográfica e Socioeconômica, número 2. Rio de Janeiro: IBGE,2013.

SADY, André; SANTANA, Stephan Bertollo. A questão da autodeclaração racial prestada por candidatos de concursos públicos. Revista Jurídica da Presidência Brasília v. 18 n. 116 Out. 2016./Jan. 2017 p. 633-665.

SILVA, Silvio José Albuquerque e. As Nações Unidas e a luta internacional contra o racismo. Brasília: Fundação Alexandre de Gusmão, 2011.

Combate ao racismo. Brasília : Fundação Alexandre de Gusmão, 2008.

Data de submissão do artigo: Maio de 2019

Data de aceite do artigo: Novembro de 2019 